\title{
O uso de sequências didáticas no ensino de Química: proposta para o estudo de modelos atômicos
}

\section{Luciana Rodrigues Leite ${ }^{1}$, Acássio Paiva Rodrigues ${ }^{2}$, Fabiana Martins Aragão ${ }^{3}$, Maria Socorro Lucena Lima $^{4}$, Francisco Nunes de Sousa Moura5, Nairley Cardoso Sá Firmino ${ }^{6}$, Francisco Jeovane do Nascimento7, Eliziane Rocha Castro7}

Resumo: Este trabalho demonstra ações de extensão desenvolvidas no Projeto "A Química nossa de cada dia", vinculado ao Curso de Licenciatura em Química da Universidade Estadual Vale do Acaraú, Sobral - Ceará. Este projeto visa melhorias no ensino de Química da Educação Básica, mediante a inserção de Sequências Didáticas (SD) nesse nível de ensino. O ensaio tem por escopo mostrar uma SD sobre modelos atômicos, aplicada a 30 alunos de uma turma de 1 o ano do Ensino Médio de uma escola pública sobralense, bem assim analisar suas contribuições para o desenvolvimento cognitivo dos discentes e o cumprimento do papel da extensão no âmbito social a que o projeto se destina. Esta SD foi elaborada mediante a colaboração entre um professor universitário, dois licenciandos (bolsistas) e o professor de Química da escola participante. Preconizou-se a utilização de atividades lúdicas (teatro científico, jogo didático, cordel), debates, dentre outros recursos que procuraram possibilitar a participação ativa dos discentes na formulação de seu conhecimento. Observou-se que a SD teve seu grau de contribuição no aspecto cognitivo dos alunos, mas, sobretudo no 'despertar' do interesse pelo estudo da Química. A parte referente aos modelos de Rutheford e Böhr, todavia, demanda maior aprofundamento. A atividade com a qual os alunos mais se identificaram foi o teatro científico, e, a seu turno, a que despertou maior atenção e participação. Por fim, destaca-se o fato de que estas ações também contribuíram para aproximar o âmbito Universitário e a sala de aula da Educação Básica.

Palavras-chave: Extensão Universitária; Educação Básica; Ciências da Natureza; Proposta Didática

The use of didactic sequence in chemistry teaching: a proposal for the study of atomic models

Abstract: This paper presents the actions of an extension project called "Our Chemistry daily", linked to the Chemistry course of the State University Vale do Acaraú, located in Sobral - Ceará. The project has aimed to promote improvements in the Basic Education chemistry teaching, through the introduction of Didactic Sequences (DS) at this level of education. The goal of this paper is to present a DS about atomic models, applied to 30 students of the $10 \mathrm{~h}$ grade from a public high school, as well as to analyze its contribution to the cognitive development of these students and to fulfill the social role in which the project bases itself. This DS was elaborated through a collaboration between a University professor, two undergraduates, and a chemistry teacher of the given school. It was prioritized the use of playful activities (such as scientific theater, educational games, and Cordel literature), debates, and other resources that sought to enable active participation of students in the construction of their knowledge. It was noted that the DS had its contribution to the cognitive learning of the students, but, above all, in the 'awakening' of their interest in the study of Chemistry. However, the part referring to the Rutheford-Böhr models demands greater depth. The activity in which students were most interested was the scientific theater, which attracted the most attention and participation. Finally, it is noteworthy that these actions also contributed to bringing the University and the Basic Education closer together

Keywords: University Extension Program; Basic Education; Natural Sciences; Didactic Proposal
Originais recebidos em

02 de abril de 2020

Aceito para publicação em

03 de julho de 2020

1 Professora do Curso de Química da Universidade Estadual Vale do Acaraú (UVA) e doutoranda em Educação no Programa de Pósgraduação em Educação da Universidade Estadual do Ceará (UECE)

lurodleite@gmail.com (autora para correspondência)

2 Graduando em Química (UVA)

3 Professora da Educação Básica SEDUC-CE.

4

Professora do Programa de PósGraduação em Educação, (UECE)

5 Mestrando em Educação Universidade Federal do Ceará (UFC)

6 Coordenadoria de Formação Docente e Educação a Distância CODEC/CED

7 Doutorandos em Educação, (UECE) 


\section{Introdução}

O ensino de Química, desenvolvido atualmente, recebe inúmeras críticas. Dentre as mais recorrentes, destacam-se os conteúdos repassados de maneira descontextualizada e a ênfase na memorização de fórmulas. Esta realidade contrapõe-se ao que as pesquisas em Ensino de Química e documentos oficiais defendem. Nos Parâmetros Curriculares Nacionais para o Ensino Médio (PCNEM), por exemplo, enfatiza-se que a aprendizagem desta disciplina deve possibilitar o entendimento das transformações químicas ocorrentes no mundo físico de modo abrangente e integrado, para que se possa julgar, com fundamentos, as informações adquiridas na mídia, na escola, com pessoas. Nessa mesma linha de pensamento, Santos e Schnetzler (1996, p. 28) destacam a ideia de que "A função do ensino de química deve ser a de desenvolver a capacidade de tomada de decisão, o que implica a necessidade de vinculação do conteúdo trabalhado com o contexto social em que o aluno está inserido".

A análise desse panorama de discrepâncias entre o real e o ideal fez emergir alguns questionamentos acerca do papel que a Universidade pode exercer. Vale ressaltar que a Lei $n^{\circ} 13.174 / 2015$, ao incluir o inciso VIII no art. 43 da Lei de Diretrizes e Bases da Educação, aponta para o entendimento de que uma das finalidades da educação superior consiste em

[...] atuar em favor da universalização e do aprimoramento da educação básica, mediante a formação e a capacitação de profissionais, a realização de pesquisas pedagógicas e o desenvolvimento de atividades de extensão que aproximem os dois níveis escolares. (Lei Federal $\left.n^{\circ} 13.174 / 2015\right)$.

Nesse sentido, pensou-se em implementar um projeto de extensão que contribuísse para o estreitamento dos laços entre o curso de Química da Universidade Estadual Vale do Acaraú (UVA), Sobral-Ceará, e os professores de Química da Educação Básica deste Município, na intenção de, com suporte no diálogo entre esses dois âmbitos, elaborar práticas que viessem convergir para melhorias nos processos de ensino e aprendizagem desta disciplina.

Essas preocupações foram o gérmen para a edificação do projeto de extensão "A Química nossa de cada dia", cujo propósito residiu em contribuir para a inserção de modificações na atual conjuntura do ensino de Química desenvolvido na Educação Básica. Para isso, foram elaboradas e aplicadas sequências didáticas (SD) no cotidiano de uma escola pública de ensino médio cearense. Um dos pontos fortes do projeto foi o diálogo estabelecido entre os sujeitos vinculados ao âmbito universitário (licenciandos e professor coordenador) e os professores da Educação Básica. Com esta ação, buscou-se identificar as necessidades desses profissionais para, desde então, trabalhar de modo colaborativo, na demanda de uma educação química mais ampla e concatenada ao contexto social em que os discentes estão inseridos.

As SD são compreendidas, na contextura deste trabalho, como ferramentas promissoras para transcender a habitual transmissão de conhecimentos inerente ao ensino de Química da atualidade. De acordo com Zabala (1998, p. 20), SD conforma "[...] uma maneira de encadear e articular as diferentes atividades ao longo de uma unidade didática", visando a ultrapassar o instrucionismo, tão comum no ambiente escolar, e favorecer o desenvolvimento da autonomia dos educandos no processo de aprender.

Por conseguinte, este escrito foi estruturado mediante a intenção de estabelecer diálogo acerca de uma SD aplicada no projeto de extensão retrocitado. Versando sobre o conteúdo modelos atômicos, esta SD foi desenvolvida em uma turma de $1^{\circ}$ ano do Ensino Médio, de uma escola pública localizada no Município de Sobral-CE. Por conseguinte, os objetivos específicos deste ensaio consistem em analisar os principais resultados obtidos com as ações desenvolvidas, enfatizando especificamente as condições efetivadas para a 
melhoria da aprendizagem dos alunos, e avaliar a potencialidade dessas ações para o cumprimento do papel da extensão na contextura social do projeto.

\section{Pressupostos teóricos}

Consoante ensina Méheut (2005), as SD são um conjunto de atividades interligadas que buscam possibilitar a aprendizagem do conhecimento científico escolar pelos estudantes. $O$ autor destaca o fato de que elas expressam quatro componentes: professor, alunos, mundo real e conhecimento científico, que, associados, privilegiam duas dimensões - a epistêmica, que abarca a relação entre o mundo material e o conhecimento científico, e a dimensão pedagógica, permeando o papel do professor, do aluno e suas interações.

A elaboração de uma SD é fruto de planejamento didático, em que a organização e evolução dos conteúdos devem ser coerentemente articuladas. Para ilustrar essa compreensão, Zabala (1998, p. 31) ressalta que, no âmbito das SD, os conteúdos de aprendizagem devem explicitar as intenções educativas, abrangendo três dimensões: "[...] dimensão conceitual - o que se deve saber?; dimensão procedimental - o que se deve saber fazer?; dimensão atitudinal - como deve ser?".

Com amparo nesses pressupostos iniciais, compreende-se que o modo de existir de uma SD é baseado no princípio da interação, pois as atividades que a compõem demandam continuidade (continuum ou sequência lógica), de maneira que a ligação entre as partes permita ao educando melhor compreensão dos conhecimentos escolares.

No tocante aos objetivos para os quais as SD são produzidas, Almouloud e Coutinho (2008) destacam a noção de que essa abordagem é largamente utilizada como expediente para coleta de dados em investigações educacionais, buscando criar condições favoráveis de ensino e aprendizagem. Zabala (1998) também evidencia que as SD são amplamente utilizadas como instrumentos de fortalecimento das relações entre a teoria veiculada nos cursos de formação de professores e as práticas desenvolvidas em sala de aula, e tem como um de seus objetivos a introdução, por intermédio de variadas modalidades de intervenção, de atividades que contribuam para melhorias da atuação docente em sala de aula. De acordo com este mesmo autor, isso só se torna possível quando se detém um conhecimento mais profundo das variáveis que intervêm nos processos de ensino e aprendizagem.

Mostra-se perceptível que, seja como veículo de coleta de dados ou instrumento de ensino, a aplicação de SD pelos docentes demanda uma preparação, uma vez que há a necessidade de se conhecer os pormenores imbricados nos processos de ensino e aprendizagem, além de uma compreensão mais ampla acerca dos aspectos políticos, sociais, econômicos e éticos em que os conteúdos estão inseridos. Essas dimensões mais amplas, inerentes ao desenvolvimento de uma SD, são também apontadas por Méheut e Psillos (2004). Eles enfatizam que o desenvolvimento das SD envolve a integração do conteúdo didático com teores científicos, abarcando dimensões práticas, sociais e técnicas.

No tocante especificamente ao ensino de Química, Fernandes e Campos (2017) ressaltam que as novas demandas e tendências educacionais preconizam que esse ensino denote uma aprendizagem mais dinâmica e contextualizada, possibilitando ao aluno um aprendizado por meio de SD, haja vista que o ensino dessa ciência se caracteriza como experimental e descritivo. Por isso, é importante que os professores compreendam a necessidade de elaborar atividades de ensino planejadas e mais atraentes, que descentralizem a aula de um padrão cuja prioridade é exclusivamente a abordagem conceitual, e proporcionem ao aluno meios de associar o conhecimento científico às suas vivências cotidianas.

Mediante esta compreensão, muitos são os trabalhos na área do ensino de Ciências enriquecedores da literatura por via formulação de propostas de SD para diversificar as possibilidades metodológicas dos 
docentes, e incentivá-los a inserir perspectivas distintas em seu fazer-pedagógico. Alguns desses exemplos estão em Rodrigues et al. (2017), que buscaram inserir a contextualização sociocultural no ensino de Química para alunos do $2^{\circ}$ ano do Ensino Médio; Berto e Lorenzetti (2019), ao elaborarem uma SD para o ensino de Física a alunos do Ensino Fundamental, objetivando a alfabetização científica dos envolvidos; e Pinheiro e Rocha (2018), quando examinaram as contribuições de uma SD, aplicada a alunos de uma escola pública do segundo segmento do Ensino Fundamental, nas aulas de Ciências, para a formação de multiplicadores no combate ao mosquito Aedes aegypti, agente transmissor da dengue, zyka vírus e chikungunya.

Esses autores listam alguns aspectos positivos gerados pela inserção de SD no ensino de Ciências. Rodrigues et al. (2017) apontam que a aplicação de situações do cotidiano dos alunos, de maneira dialogada, contribui para envolvê-los com o tema abordado, auxiliando no despertar do pensamento crítico. Berto e Lorenzetti (2019) corroboram e adicionam a noção de que o uso das SD possibilita o desenvolvimento da Alfabetização Científica no contexto escolar. Pinheiro e Rocha (2018) exprimem que, ao se propor uma aprendizagem por meio da interação, participação e discussão dos estudantes, as SD podem formar multiplicadores de conhecimento na comunidade local, havidos como meios essenciais para a tomada de decisões assentadas nas perspectivas da abordagem Ciência, Tecnologia e Sociedade (CTS).

\section{Pressupostos metodológicos}

O estudo sob relatório é fundamentado na abordagem qualitativa e do tipo relato de experiência. De acordo com Chizzotti (2003), o termo qualitativo implica uma partilha densa com pessoas, fatos e locais que constituem objetos de pesquisa, para extrair desse convívio os significados. A experiência relatada configura a primeira SD desenvolvida no projeto de extensão "A Química nossa de cada dia", que versou sobre o conteúdo modelos atômicos. Foi organizada em cinco momentos distintos, porém complementares, e desenvolvida em uma escola de Ensino Médio regular, situada em zona vulnerável do Município de Sobral-CE, em uma turma de $1^{\circ}$ ano, composta por 30 alunos com baixo rendimento, na disciplina Química.

Participaram dois licenciandos em Química (bolsistas do Projeto), um professor universitário (coordenador do Projeto) e um professor da Educação Básica (regente da turma em que a SD foi aplicada). O planejamento ocorreu de modo colaborativo, com participação ativa do professor regente, tendo-se optado pela utilização de metodologias e recursos diversificados, tais como atividades lúdicas e debates. As ações desenvolvidas intentaram desenvolver uma compreensão mais ampla dos alunos a respeito do conhecimento científico, considerando os aspectos históricos, sociais, econômicos, éticos, entre outros. Além disso, a contextualização foi utilizada, visando a auxiliar na atribuição de sentido ao conteúdo apreendido.

Para analisar a influência da SD na aprendizagem ou no desenvolvimento de outras habilidades, foi aplicado um questionário misto contendo quatro perguntas, três das quais versavam sobre saberes específicos atinentes ao conteúdo mostrado, ao passo que uma questão buscou identificar as impressões dos discentes sobre as metodologias adotadas (Suplemento S1). A análise dos dados deste questionário está expressa na descrição da aula cinco, disposta na próxima seção. Esses indicadores, juntamente com as percepções do professor regente e dos bolsistas, foram imprescindíveis para a avaliação da referida SD e redimensionamento das ações, para elaboração das sequências seguintes.

\section{Sequência Didática sobre modelos atômicos}

\section{Aula 1 - Fundamentos históricos da teoria atômica}

A primeira aula consistiu na sondagem dos conhecimentos prévios dos estudantes e introdução ao conteúdo. Foram abordados alguns conceitos de atomismo e, sobretudo, o percurso histórico da teoria atômica, 
porquanto se supõe, de saída, que é essencial aos educandos a compreensão do contexto em que os conhecimentos científicos foram sendo edificados, visto que aprender ciência significa entender um processo epistemológico, discutindo as teorias e leis, compreendendo que ela está em constante evolução (Melo \& Neto, 2013). Deste modo, concorda-se com Beltran et al. (2014) quando destacam que abordar a história da Ciência proporciona ao estudante pontos de reflexão e debate em relação a esses conceitos, buscando o aperfeiçoamento desta ciência e aproximando os conhecimentos químicos do cotidano dos aprendentes.

Como proposta metodológica inicial, recorreu-se a uma "tempestade de ideias", no tentame de identificar os conhecimentos prévios dos estudantes sobre 'o que são os átomos' (com anotação dos principais aspectos no quadro branco). Na sequência, uma peça de teatro científico foi utilizada como recurso para introdução do conteúdo, concedendo ênfase à origem do atomismo e à evolução histórica do conceito de átomo. De acordo com Valério et al. (2019), o teatro é veículo de incentivo à formulação do conhecimento científico, uma vez que pode promover a motivação e envolvimento dos alunos com as atividades propostas, além de estimular o uso e apropriação da linguagem científica.

A peça 'História Atômica' foi escrita e encenada pelos licenciandos (bolsistas) para os alunos da Educação Básica, e, a seguir, na Figura 1, consta um trecho do roteiro da referida peça.

Os alunos, inicialmente, mostraram 'estranheza' em relação ao modo como os bolsistas estavam vestidos. Riram e demoraram para se concentrar, mas o professor regente da turma (e também narrador da peça) paralisou a atividade e fez um momento de reflexão no que concerne às possibilidades de aprendizado oriundas daquela ocasião. Na sequência, solicitou que os estudantes fizessem anotações sobre a história que estava sendo narrada ou de dúvidas surgentes no decorrer da apresentação, para que, ao final, fosse realizada uma seção de debate.

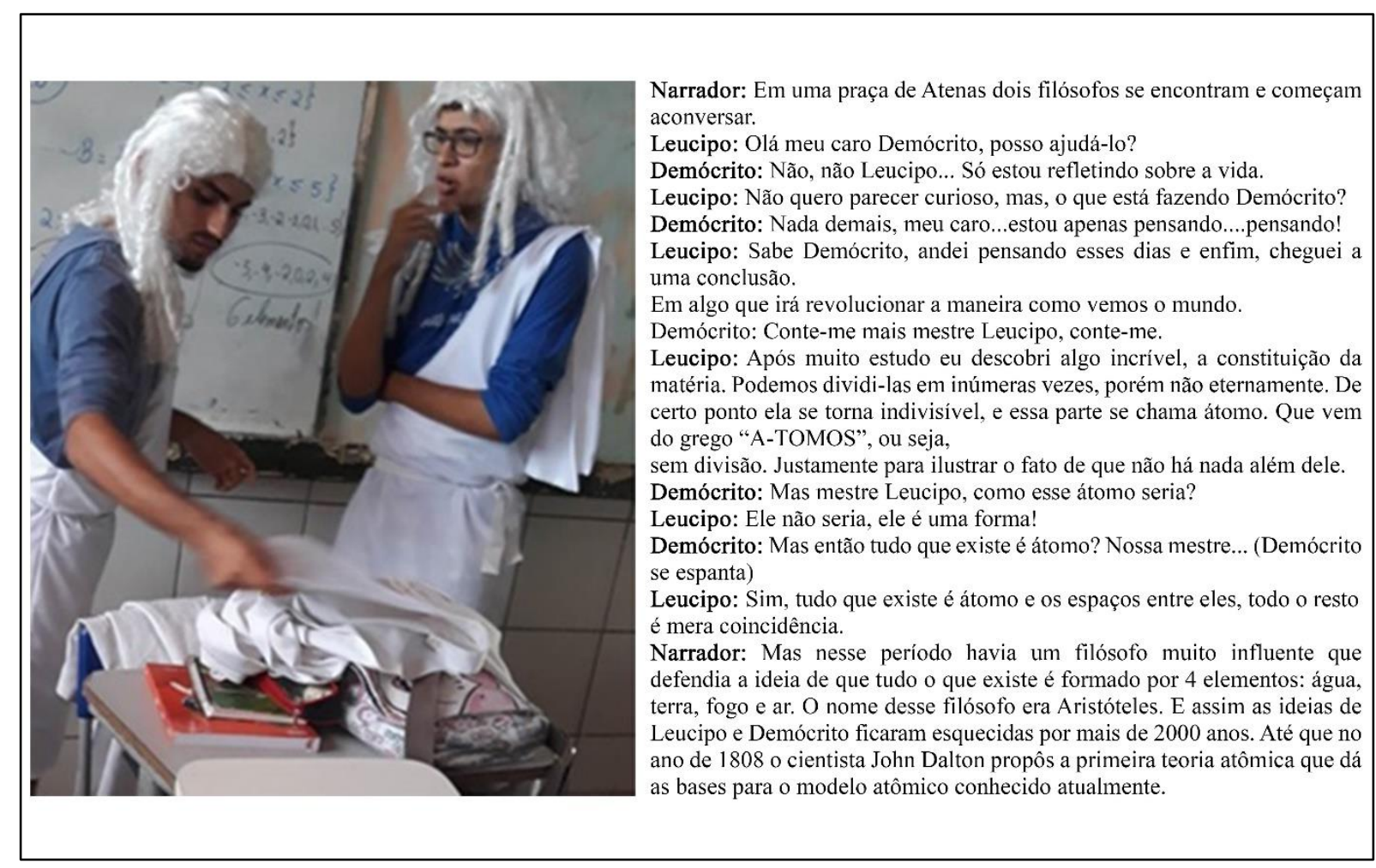

Figura 1. Peça de teatro elaborada e encenada pelos bolsistas, para alunos da Educação Básica, abordando a origem e evolução histórica do conceito de átomo. Fonte: dos autores. 
Após a apresentação da peça, foi realizada uma discussão entre bolsistas, alunos e professor acerca da história narrada, com a intenção de aprofundar os conhecimentos sobre a temática. Os alunos foram estimulados a discorrer a respeito dos acontecimentos em formato de debates com a mediação dos licenciandos/bolsistas e do professor de Química. Altarugio et al. (2010) ressaltam que essa estratégia de aprendizagem, baseada em debates, expressa inúmeras vantagens aos docentes e discentes, proporcionando uma aprendizagem significativa pois, "[...] oferece aos alunos a oportunidade de exporem suas ideias prévias a respeito de fenômenos e conceitos científicos num ambiente estimulante" (p. 27).

A princípio, os alunos se mostraram tímidos, mas, aos poucos, de acordo com os questionamentos dos bolsistas e intervenções do professor de Química, o diálogo foi fluindo e eles se mostraram mais receptivos para contribuir com o debate. Além disso, pôde-se observar que a peça teatral, mesmo com poucos recursos, conseguiu chamar atenção desses sujeitos e contribuir para o alcance dos fundamentos históricos imbricados na constituição da teoria atômica. Mostrou-se relevante, nesse momento, a possibilidade de destacar a provisoriedade do conhecimento científico e a relação direta da formulação desses conhecimentos com o desenvolvimento social, econômico, político, cultural e científico da sociedade.

\section{Aula 2 - A evolução dos modelos atômicos}

Na segunda aula, foi abordado o percurso evolutivo dos modelos atômicos, por meio de uma aula expositiva dialogada, na qual se utilizou como recurso uma linha do tempo dos modelos atômicos (Figura 2), a fim de representar o avanço da atomística ao largo da evolução do pensamento científico. Esta aula foi desenvolvida mediante os objetivos de identificar as várias partículas constitutivas do átomo e suas características; reconhecer a evolução da teoria atômica e a necessidade de elaboração de modelos para ilustrar essa evolução; comparar esses modelos, relacionando suas características ao momento histórico no qual foram elaborados.

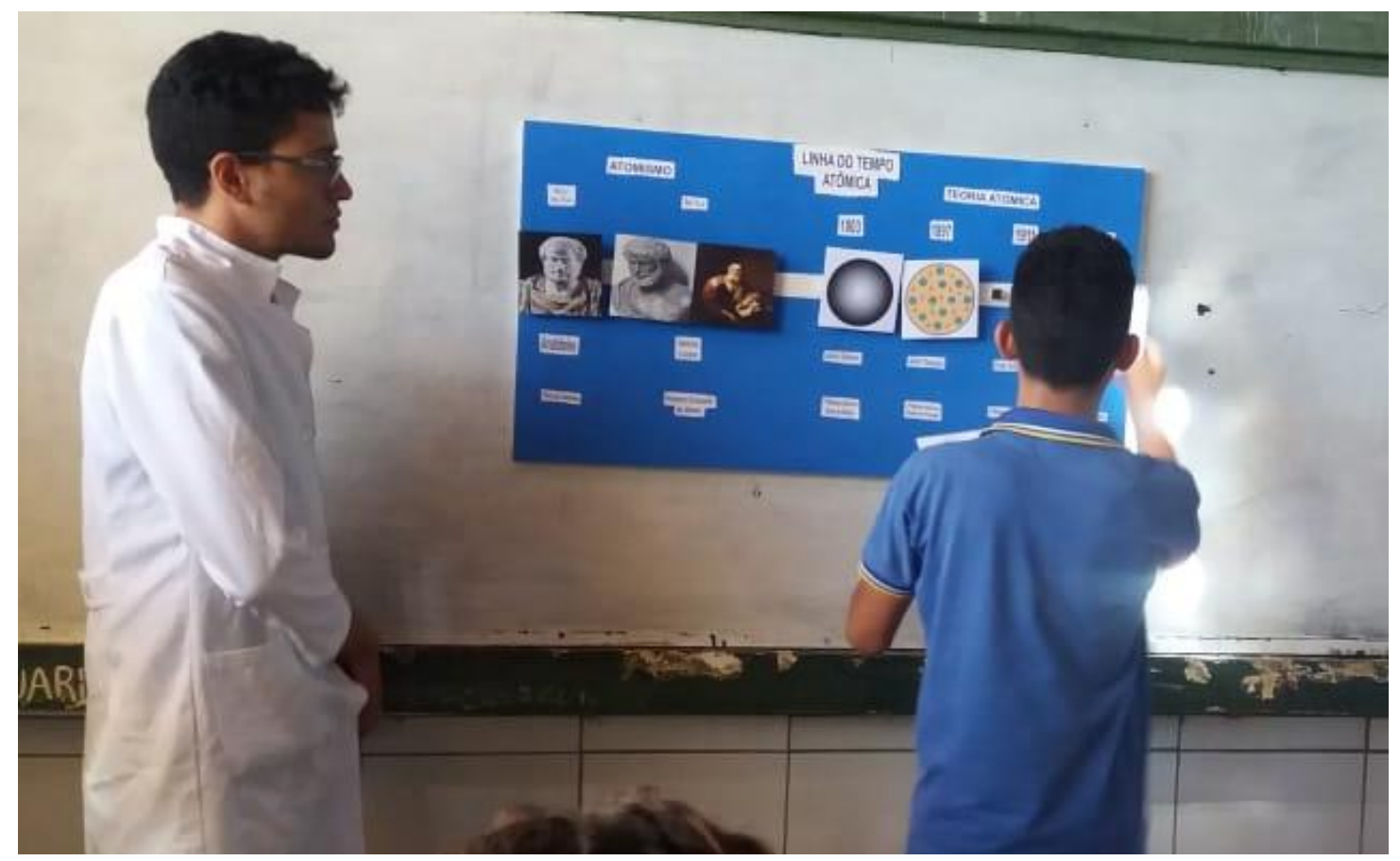

Figura 2. Linha do tempo 'Evolução dos modelos atômicos' utilizada para representar o avanço da atomística ao longo da evolução do pensamento científico. Fonte: dos autores. 
Neste intento, os alunos foram divididos em grupos e convidados a participar da aula, fazer anotações e possíveis questionamentos durante a exposição dialogada realizada pelos bolsistas, juntamente ao professor regente, que abordou desde a ideia de átomo na Grécia Antiga, passando pelos modelos atômicos de Dalton, Thomson, Rutheford e Böhr. Em seguida, os grupos foram convidados a preencher a linha do tempo, relacionando os cientistas aos seus respectivos modelos atômicos e características. Conforme os grupos acertavam a relação autor-modelo-características, iam sendo realizados questionamentos referentes aos aspectos históricos de evolução do pensamento científico que contribuíram para a constituição desses modelos.

Foram estabelecidas regras para a participação dos grupos, no intuito de propiciar a inserção de todos na atividade. Demais disso, buscou-se que os alunos identificassem e compreendessem, em especial, os acontecimentos científicos que foram impulsionando a evolução dos modelos atômicos no decorrer do tempo, assim como sua provisoriedade (seu caráter transitório). Além disso, mostra-se precípuo ressaltar que a metodologia adotada se baseou na perspectiva de Cool e Solé (1996), segundo a qual o professor norteia o aprendizado do aluno, sujeito da ação, atuando como um guia. Nesse método construtivista de ensino, a orientação é fundamental para o desenvolvimento pessoal e cognitivo do discente.

Pôde-se observar que, inicialmente, os alunos se mostraram bastante participativos e motivados, fazendo perguntas e tirando suas dúvidas sobre o conteúdo oferecido. A maior parte da turma teve participação ativa na atividade, mesmo com algumas dúvidas, que se mostraram normais e foram sendo esclarecidas pelos bolsistas e o professor. Puderam ser identificadas, todavia, algumas limitações nesta atividade, mormente em virtude da repetição no preenchimento da linha do tempo por todos os grupos de alunos (um de cada vez). Do terceiro grupo em diante, a turma se dispersou, o que reitera a necessidade de se pensar em uma dinâmica diferente para a futura aplicação deste recurso, em sala de aula.

\section{Aula 3 - Aprofundamento dos conhecimentos}

Considerando-se o objetivo de aprofundar e rever os conhecimentos adquiridos nas aulas anteriores, os conteúdos abordados nesta fase foram o histórico da teoria atômica, átomo e suas partículas, modelos atômicos. O recurso adotado foi o jogo 'Trilha atômica' (Figura 3), confeccionado em material EVA, contendo 52 casas. Foram produzidas 50 cartas que contemplavam perguntas relacionadas ao conteúdo estudado. Para participar do jogo, a turma foi dividida em três equipes, que receberam pinos para percorrerem as casas sorteadas ao jogar um dado. No decorrer do jogo, as equipes deveriam obedecer às orientações da trilha, que continha também casas com charadas e curiosidades sobre os modelos atômicos e os cientistas. Venceu o jogo a equipe que primeiro chegou ao final da trilha.

De acordo com Felício e Soares (2018), a utilização de jogos didáticos provoca alguns efeitos e mudanças no comportamento dos estudantes, além de conformarem atividades que possuem o potencial de atender as necessidades formativas dos sujeitos, dentre elas a aprendizagem de conceitos, desenvolvimento de habilidades e competências; motivação e socialização em grupos.

No decorrer da aplicação do jogo, foi perceptível o fato de que muitos alunos puderam sanar dúvidas acerca do conteúdo, aprender com a ajuda dos colegas de classe, superar concepções errôneas, adquirir conhecimentos sobre o assunto, além de desenvolver habilidades de trabalho em equipe. Mesmo assim, identificou-se o fato de que grande parte dos alunos ainda apresentou dúvidas, principalmente em relação aos modelos de Rutheford e Böhr. Desse modo, optou-se por, na aula seguinte, dar maior ênfase a esses dois modelos, com vistas a contribuir para melhorias no aprendizado dos discentes. 


\section{Aula 4 - 'Cordelizando' a teoria atômica}

Na quarta aula foi utilizado como recurso um cordel, abordando sucintamente as características dos modelos atômicos (discutidas anteriormente), dando maior ênfase aos modelos de Rutheford e Böhr e às partículas que os constituem (Ver Figura 4). Os objetivos desta aula foram: analisar as características dos modelos atômicos de Rutheford e Böhr, identificar as características que os distinguem dos modelos anteriores, e relacionar as características desses modelos ao momento histórico no qual foram elaborados e à evolução do conhecimento científico daquele período.

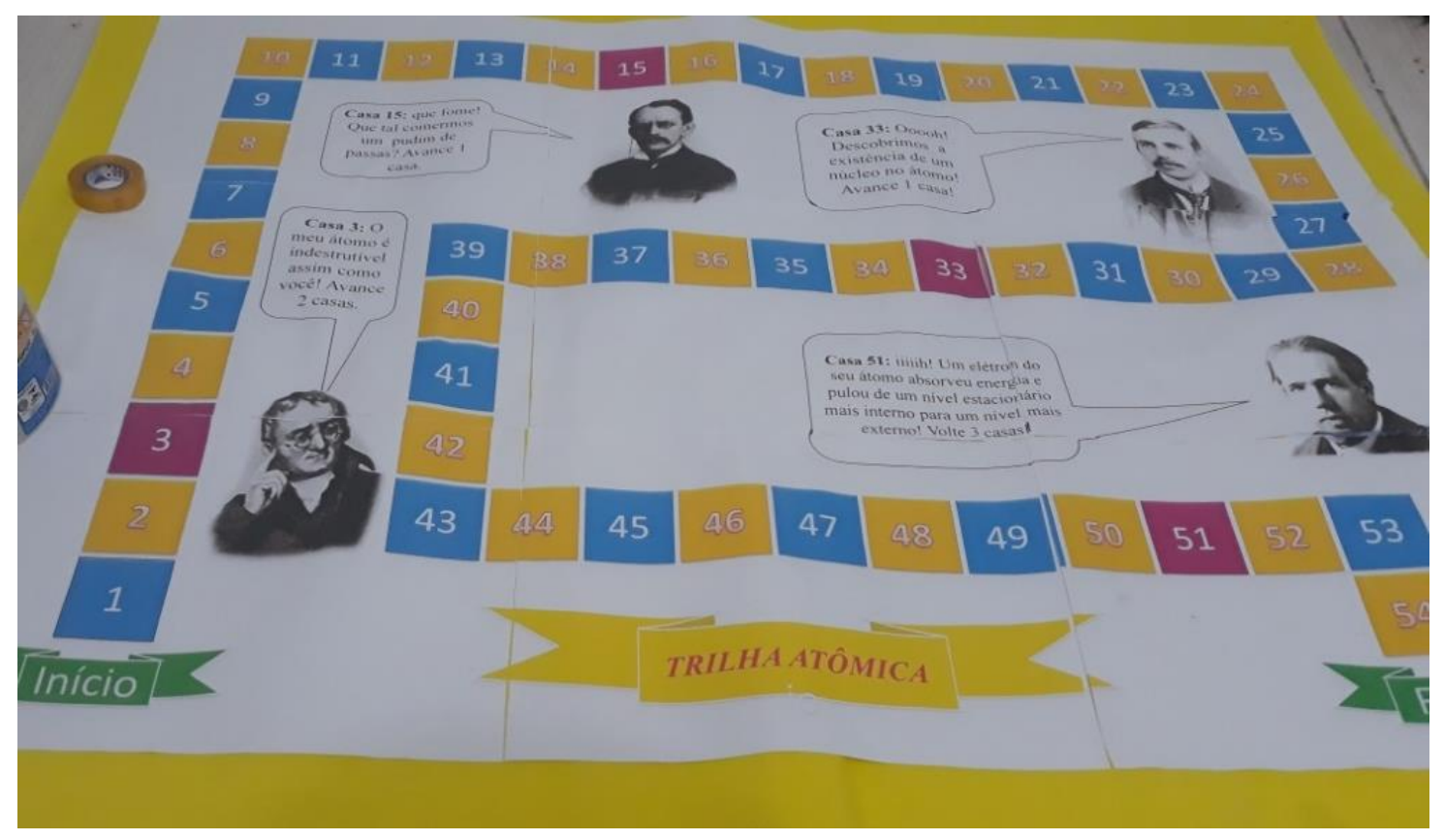

Figura 3. Jogo "Trilha Atômica", confeccionado pelos bolsistas para revisão dos conhecimentos adquiridos nas aulas anteriores. Fonte: material adaptado $\underline{1}$.

\begin{tabular}{|cc|}
\hline O ATOMISMO EM CORDEL & FORMANDO UMA HIPÓTESE \\
É COM GRANDE SATISFAÇÃO & DE QUE TUDO ERA FORMADO \\
QUE ABORDO ESSE TEMA & POR PARTICULAS INDIVISIVEIS \\
A HISTÓRIA DO ATOMISMO & QUE DERAM O NOME DE ÁTOMO \\
EM VERSOS NESSE POEMA & {$[\ldots]$} \\
FOI EM UMA ÉPOCA BEM DISTANTE & VAMOS FALAR DOS MODELOS ATÔMICOS \\
E TAMBEM MUITO ABUNDANTE & E OS CIENTISTAS QUE OS IDEALIZARAM? \\
EM INDAGAÇÕES E DILEMAS. & O PRIMEIRO FOI JOHN DALTON, \\
{$[\ldots .]$.} & QUE FOI LOGO A DIVULGAR \\
O BERÇO DA HUMANIDADE É A GRÉCIA LÁ & QUE O ATOMO ERA MAÇICO, INDIVISIVEL \\
NASCIA-SE PARA PENSAR. & [...] \\
E QUEM DIGA O FILÓSOFO ARISTÓTELES QUE & E INQUEBRÁVEL, CONHECIDO COMO BOLA DE BILHAR \\
FOI LOGO A DIVULGAR & ENQUANTO ISSO RUTHERFOR DEU A IDEIA DO MODELO \\
QUE TUDO NA TERRA ERA FEITO DE & PLANETARIO COM ORBITAS CIRCULARES \\
QUATRO ELEMENTOS: & MOGO EM SEGUIDA VEIO BOHR PARA APRIMORAR ESSES \\
TERRA, AGUA, FOGO E AR. & MODELOS EXEMPLARES. \\
AÍ CONTRIBUINDO BASTANTE, ESSE DOIS & FORAM ALÉM: \\
LEUCIPO E DEMÓCRITO & COM SUAS ÓRBITAS ELÍPTICAS O ÁTOMO SOFREU \\
PENSARAM COMO NINGUÉM & TRASNFORMACCÕES AO LONGO DA HISTORIA \\
& AGORA VAMOS RESPONDER UM QUETIONÁRIO \\
& GUARDE ELES NA MEMORIA \\
\hline
\end{tabular}

Figura 4. Trechos do Cordel Químico utilizado para analisar as características dos modelos atômicos, dando maior ênfase aos modelos de Rutheford e Böhr. Fonte: dos autores. 
Para iniciar a aula, foi necessário, primeiramente, mostrar esse gênero textual à turma - o cordel. Na sequência, foram enfatizados os fatos históricos que culminaram na elaboração da teoria atômica e estimuladas discussões acerca do tema no decorrer da leitura do cordel, promovendo um ambiente frutífero em discussão e aprendizado pelos alunos, e aprofundando as discussões na parte em que se abordava as características dos modelos de Rutheford e Böhr.

Após a leitura e discussão do cordel, os bolsistas desenvolveram uma exposição dialogada acerca das características dos modelos de Rutheford e Böhr, e, na sequência, foram resolvidos exercícios, no intuito de contribuir para o aprofundamento dos conhecimentos dos discentes. É conveniente ressaltar que os estudantes se mostraram pouco participativos no momento da resolução dos exercícios, embora estes tenham sido elaborados de modo contextualizado.

\section{Aula 5 - Avaliação do processo}

Na quinta aula, foi aplicado um questionário avaliativo aos discentes, a fim de mensurar o influxo que a SD teve no aprendizado do conteúdo, assim como suas impressões acerca da metodologia adotada. Observouse que todas as estratégias tiveram boa aceitação, pois, ao serem questionados sobre as atividades que mais contribuíram para o seu aprendizado, os discentes citaram todos os momentos pedagógicos adotados, detectando o teatro científico como o momento mais significativo.

Em decorrência desses resultados, é oportuna a ocasião de evidenciar que o teatro científico é um recurso pouco utilizado no concerto escolar, e talvez por isso tenha despertado a curiosidade dos estudantes. Importa destacar, ainda, o potencial desse instrumento pedagógico no despertar do interesse dos espectadores pelo assunto abordado, uma vez que ele é considerado um instrumento interdisciplinar (Bezerra et al., 2018).

No que se refere à avaliação do aprendizado dos conteúdos específicos, observou-se que a maioria dos alunos respondeu corretamente a questão relacionada à identificação das partículas fundamentais da estrutura do átomo, logrando relacionar as características dos modelos atômicos de Dalton e Thomson, enquanto um número considerável errou as questões vinculadas aos modelos de Rutheford e Böhr. Ressalta-se que, de acordo com o professor regente da disciplina Química na referida turma, houve significativa melhora no rendimento dos participantes. $O$ aprendizado em relação aos modelos atômicos de Rutheford e Böhr, todavia, ainda foi insuficiente.

Esse fato se assemelha ao observado por Simões Neto e Prates Junior (2012), ao proporem situações-problema elencando os modelos atômicos de Rutheford e Böhr, demonstrando uma fragilidade nos processos de ensino e aprendizagem quando se abordam esses dois modelos. Compreende-se que, dentre as causas para que isso ocorra, se insere o fato de esses dois temas exprimirem conceitos mais complexos e abstratos, de modo que, para sanar essas dificuldades, seria necessário mais tempo de aplicação da SD, com a inserção de maior número de aulas e outras estratégias didáticas, pois o conteúdo exige um esforço cognitivo maior em virtude da abstração que há em sua abordagem.

Por conseguinte, observou-se a importância do procedimento avaliativo e, maiormente, das reflexões dele oriundas, por propiciarem o desenvolvimento de uma intervenção por parte do professor regente, nas aulas seguintes. De acordo com Libâneo (1993), a avaliação é uma tarefa pedagógica, necessária e permanente ao trabalho docente, por meio da qual se obtêm os resultados que serão comparados aos objetivos propostos, orientando o fazer pedagógico. Transpondo essa ideia, a observação desses pormenores contribuiu para a inserção de melhorias na elaboração das SD seguintes. 


\section{Considerações finais}

Este ensaio se propôs demonstrar a primeira SD desenvolvida no âmbito do Projeto de extensão 'A Química nossa de cada dia'. Os resultados obtidos permitiram analisar as implicações desta SD no aprimoramento do conhecimento químico, por parte dos educandos envolvidos. Ademais, buscou-se evidenciar o potencial desse instrumento pedagógico para atingir os objetivos inerentes aos propósitos da extensão.

Destaca-se, a priori, o argumento de que a relevância social desta investigação residiu na intenção de estimular o diálogo entre a pesquisa em ensino de Ciências e a sala de aula da Educação Básica, fato que pôde ser consumado mediante o trabalho colaborativo entre o coordenador do projeto (professor universitário), os bolsistas (licenciandos), e o professor da Educação Básica, contribuindo para o estreitamento dos laços entre esses três segmentos e o consequente compartilhamento de conhecimentos teóricos e práticos, com arrimo nas experiências vivenciadas por parte de cada um. Nesse sentido, concretizou-se o propósito de ações de extensão no âmbito social, eixo essencial do ensino superior.

Observou-se, ainda, que a aplicação da referida sequência se mostrou significativa no estímulo à aprendizagem e criatividade dos alunos, pois contribuiu para despertar o interesse dos discentes no aprendizado de Química. Consequentemente, a SD serviu para estimular o trabalho em equipe, aprimorar a capacidade de observação, o registro de informações e a reflexão sobre a provisoriedade do conhecimento científico, a considerar o contexto histórico em que este vai sendo edificado, dentre outros aspectos. Com efeito, a experiência, como um todo, contribuiu para o aprendizado de conteúdos procedimentais, atitudinais e conceituais, por parte dos estudantes. Identificaram-se, ainda, teores não assimilados de modo efetivo pelos discentes, o que viabilizou o desenvolvimento de intervenções futuras por parte do professor regente.

Por fim, reitera-se a ideia de haver a expectativa de que essa SD sirva de inspiração para outros professores de Química da Educação Básica. Desta maneira, os docentes podem aplicar esta metodologia em sala de aula, posteriormente, com as devidas adequações que considerarem pertinentes. Pode-se enfatizar também o potencial motivador para a inserção do uso de SD no ensino de Química desse nível de ensino, com a posterior elaboração de suas sequências.

\section{Agradecimentos}

À Pró-Reitoria de Extensão e Cultura (PROEX) e à Pró-Reitoria de Assuntos Estudantis (PRAE) da Universidade Estadual Vale do Acaraú (UVA), Sobral-CE.

\section{Contribuições de cada autor}

O autor L. R. L participou como coordenador e orientador do projeto, atuando em todas as etapas metodológicas, realizando a parte de planejamento do artigo, escrita, revisão crítica e redação final. $\mathrm{O}$ autor $\mathrm{A}$. P. R participou de todas as etapas da pesquisa, desde a metodologia do projeto à redação do manuscrito. $\mathrm{O}$ autor F. M. A. participou como integrante do projeto na realização das atividades metodológicas e atuou na revisão da literatura, análise e tabulação dos dados. Os autores M. S. L. L. e F. N. S. M. desenvolveram a parte de planejamento e sistematização dos resultados e discussões, enquanto os autores N. C. S. F., F. J. N. e E. R. C. fizeram análises críticas do texto e deram contribuições à redação final deste manuscrito. 


\section{Notas}

${ }^{1}$ Material adaptado de: https://www.slideshare.net/cristianinakao/jogo-1-trilha-do-tomo

\section{Referências}

Almouloud, S. A., \& Coutinho, C. D. Q. E. S. (2008). Engenharia Didática: Características e seus usos em trabalhos apresentados no GT-19/ANPEd. Revista Eletrônica de Educação Matemática, 3(1), 62-77.

Altarugio, M. H., Diniz, M. L., \& Locatelli, S. W. (2010). O debate como estratégia em aulas de Química. Química Nova na Escola, 32(1), 26-30.

Beltran, R. H. M., Saito, F., \& Trindade, P. S. L. (2014). História da Ciência para formação de professores. São Paulo: Ed. Livraria da Física.

Berto, J. A., \& Lorenzetti, L. (2019). Sequência didática para estudo da queda dos corpos: Uma possibilidade de educação científica. Revista Rede Amazônica de Educação Matemática, 7(2), 261-279.

Bezerra, R. S., Nunes, A. O., \& Alves, L. A. (2018). O Teatro Científico: Uma ferramenta interdisciplinar. Revista Eletrônica Científica Ensino Interdisciplinar, 4(10), 140-151.

Chizzotti, A. (2003). A pesquisa qualitativa em Ciências Humanas e Sociais: Evolução e desafios. Revista Portuguesa de Educação, 16(2), 221-236.

Coll, C., \& Solé, I. (1996) A interação professor/aluno no processo de ensino e aprendizagem. In C. Cool, J. Palacios, \& A. Marchesi, (Eds.), Desenvolvimento psicológico e educação: Psicologia da educação. (pp. 281-297). Porto Alegre: ArtMed.

Felício, C. M., \& Soares, M. H. F. B. (2018). Da Intencionalidade à responsabilidade lúdica: Novos termos para uma reflexão sobre o uso de jogos no ensino de química. Química Nova na Escola, 40(3), 160-168.

Fernandes, L. S., \& Campos, A. F. (2017). Tendências de pesquisa sobre a resolução de problemas em Química. Revista Electrónica de Enseñanza de las Ciencias, 16(3), 458-482.

Libâneo, J. C. (2013). Didática. 2. ed. São Paulo: Cortez.

Melo, M. R., \& Neto, E. G. L. (2013). Dificuldades de ensino e aprendizagem dos modelos atômicos em Química. Química Nova na Escola, 35(2), 112-122.

Méheut, M. (2005). Teaching-learning sequences tools for learning and/or research. In K. Boersma, M. Goedhart, O. De Jong, \& H. Eijkelholf (Eds.), Research and the quality of Science Education. (pp. 195-207). Dordrecht: Springer.

Méheut, M., \& Psillos, D. (2004). Teaching-learning sequences: Aims and tools for science education research. International Journal of Science Education, 26(5), 515-535.

Pinheiro, R. F., \& Rocha, M. B. (2018). Contribuição de uma Sequência Didática no ensino de ciências para combate ao Aedes aegypti. Ensino, Saúde e Ambiente, 11(3), 186-201.

Rodrigues, J. B. S., Santos, P. M. M., Lima, R. S., Saldanha, T. C. B., \& Weber, K. C. (2017). O milho das comidas típicas juninas: Uma sequência didática para a contextualização sociocultural no ensino de Química. Química Nova na Escola, 39(2), 179-185.

Santos, W. L. P., \& Schnetzler, R. P. (1996). Função social: O que significa ensino de Química para formar o cidadão? Química Nova na Escola, 2(4), 28-34.

Simões Neto, J. E., \& Prates Júnior, M. S. L. (2012). Situações-Problema como estratégia didática para o ensino de modelos atômicos. Revista Brasileira de Ensino de Ciência e Tecnologia, 8(3), 181-201. 
Valério, J. S., Silva, L. C., \& Oliveira, J. R. S. (2019). Contribuições do teatro de divulgação científica por meio da peça o mágico de $\mathrm{O}_{2}$. Ensino de Ciências e Tecnologia em Revista, 9(2), 67-81.

Zabala, A. (1998). A Prática Educativa: Como educar. Porto Alegre: Artmed.

Como citar este artigo:

Leite, L R., Rodrigues, A. P., Aragão, F. M Lima, M. S. L., Moura, F. N. S., Firmino, N. C. S., do Nascimento, F. J., \& Castro, E. R. (2020). O uso de sequências didáticas no ensino de Química: Proposta para o estudo de modelos atômicos. Revista Brasileira de Extensão Universitária, 11(2), 177-188. https://periodicos.uffs.edu.br/index.php/RBEU/article/view/ $11429 / \mathrm{pdf}$ 